\title{
Gender-based clinical study on the association of cognitive impairment with drinking and smoking
}

\author{
Yingying Fu' ${ }^{1}$, Xiaoli Chen ${ }^{2}$, Guoping Zhang ${ }^{3}$, Shunda Wang ${ }^{4 *}$ \\ ${ }^{1}$ Department of Emergency, ${ }^{2}$ Department of Neurology, ${ }^{3}$ Department of Computed Tomography, ${ }^{4}$ Department of Rehabilitation \\ Medicine, Shaanxi Provincial People's Hospital, Xi'an, Shanxi 710068, China
}

*For correspondence: Email: shundawang6@hotmail.com; Tel/Fax: 0086-15829307937

\begin{abstract}
Purpose: To evaluate the relationship between alcohol consumption and cigarette smoking among the elderly population of a Chinese city with a risk of developing cognitive decline and dementia.

Methods: In this study, 1687 participants from the suburban town of Yanliang in Xi'an Sub-province, Shanxi Province, China in the age group of $60-65$ years and who have not develop cognitive decline were assessed over a 6-year period. The study involved the evaluation of gender-based effect on alcohol consumption and smoking cigarette and its impact on cognitive functions.

Results: The study observed that smokers have a higher risk of cognitive decline than non-smokers (odds ratio $=1.51 ; 95 \% \mathrm{Cl}=(1.07-2.11)$. Interestingly, the odds ratio of the smokers among the female subjects was 1.54; $95 \% \mathrm{Cl}(1.02$ - 2.49) compared to female non-smokers. Moreover, a dosedependent relationship was observed for those female smoker with higher pack-years compared to nonsmokers $(p=0.003)$. On the other hand, regular alcohol consumption also increased the possibility of dementia and cognitive decline (odds ratio $=1.69 ; \mathrm{Cl}$ at $95 \%=(1.03-2.75)$, hence a dose-dependent relationship was observed between male users $(p=0.042)$.

Conclusion: The results suggest that alcohol consumption and smoking are linked with cognitive decline among the female subjects in the age group of $60-65$ years. Thus, the relationship between these factors is characterized by gender difference which may be due to female sex hormones.
\end{abstract}

Keywords: Cognitive health, Alcohol consumptions, Smoking, Elderly population

\begin{abstract}
This is an Open Access article that uses a funding model which does not charge readers or their institutions for access and distributed under the terms of the Creative Commons Attribution License (http://creativecommons.org/licenses/by/4.0) and the Budapest Open Access Initiative (http://www.budapestopenaccessinitiative.org/read), which permit unrestricted use, distribution, and reproduction in any medium, provided the original work is properly credited.

Tropical Journal of Pharmaceutical Research is indexed by Science Citation Index (SciSearch), Scopus, International Pharmaceutical Abstract, Chemical Abstracts, Embase, Index Copernicus, EBSCO, African Index Medicus, JournalSeek, Journal Citation Reports/Science Edition, Directory of Open Access Journals (DOAJ), African Journal Online, Bioline International, Open-J-Gate and Pharmacy Abstracts
\end{abstract}

\section{INTRODUCTION}

The population of the Chinese people which is $\geq$ 65 years constitutes around $15 \%$ as per 2010 census [1]. The number of these elderly populations is increasing day by day. Thus, a social burden comprising of cognitive health issues such as dementia, loss of cognitive functions, sensory impairments, malnutrition, physical injury has become an important issue [2]. Among the elderly Chinese population, cognitive decline or cognitive impairment is the major health issue [2]. Thus, there is an urgent need for checking the development of cognitive impairment among these elderly populations which can be prevented by identifying the changeable risk factors. Additionally, there are various reports that suggest dementia or 
cognitive decline in aged population is associated with smoking and alcohol consumption [2,3]. In fact, the association of cognitive impairment between drinking alcohol and smoking is widely discussed during the recent years. On the contrary, there are also reports which suggest that nicotine improves short-term cognitive performance by inhibiting the amyloid formation [3]. In addition, $\mathrm{Xu}$ et al reported that moderate consumption of alcohol protect against dementia while excessive consumption increases the risk for dementia [4]. When it comes to the gender difference in the elderly population, women constitute half of the smokers $[5,6]$. Hence, gender difference is an important factor while studying the health effects of the cognitive decline. Although many studies have reported on the health effects related to smoking and alcohol consumption and its association with cognitive decline, several studies lack to focus and report on the gender differences [7-9]. In fact, many researchers failed to report on the physical and social health that is linked with cognitive decline during the follow-up period [7-10]. However, the association between smoking and cognitive decline is still in the debate and controversial [8,9]. Therefore, the present study aim at the prospective study of the elderly Chinese Community population to assess the association between alcohol consumption and smoking and cognitive decline during a 6 year study period. The present study is an attempt to evaluate the gender-based association of cognitive impairment between smoking status and alcohol consumption.

\section{METHODS}

\section{Compliance with ethical standards}

The protocol was approved by the Institutional Ethical Committee vide Ref No.SPPH/EthicsAnim/2016/07/25A. All procedures were performed in accordance with the 1964 Helsinki Declaration and its later amendments or similar ethical standards [11]. Informed consent was also obtained from all the individual participants included in the investigation. Verbal informed consent was taken from the illiterate participants. Therefore written consent was also taken from the parents or guardians of these participants. Verbal interviews and personal interviews were carried out by the experienced medical students and practitioner.

\section{Study population}

Data were obtained from the inhabitants of the suburban town of Yanliang under Xi'an subprovince, Shanxi Province, China, which has a population of 150,130 . The study subjects were aged 60 - 65 years and the study area covers around 436.13 square $\mathrm{km}$. The study subjects were identified based on community resident information and registration from the Community Information Center. Their actual date of birth was cross-checked for verification purposes. Followup evaluations were started in 2010 and completed in 2016. A total of 2034 participants volunteered in the evaluation; however, 348 participants were not available for further evaluations. Hence, 1687 participants took part in the follow-up period.

\section{Data collection}

Data collection was carried out based on personal interviews with experienced medical personnel, doctors and students. The volunteers/participants were briefly described about the main purpose of the survey. Finally, screening was carried out for cognitive impairment and depressive symptoms for those participants who were willing to take part in the program. Their daily activities, lifestyle and marital status, education were also recorded (Table 1). The questionnaire used in the followup period was recorded for their smoking status. The status includes whether the participant is a present-smoker, ex-smoker or a non-smoker.

The details of smoking duration and number of cigarettes smoked per day were obtained from the present-smoker and ex-smoker. Based on the equation developed by Park et al [12] they were classified into two categories: high ( $\geq 50 \%)$ and low $(<50 \%)$. Similarly, the questionnaire used in the follow-up period for the alcohol consumption status include the details of present alcohol consumption and its rate of consumption. The study subjects were further classified as non-drinker, moderate-drinkers ( 1 to 4 times per week), and regular-drinkers (more than 4 times per week). Global cognitive functioning was evaluated and measured with a modified version of the Mini-Mental State Examination-Chinese (MMSE-C) [13].

The content was mostly translated literally without any deviations from the original questionnaire. Some questions were modified to adjust with the cultural criteria for Chinese tradition [13]. Cognitively impaired subjects were classified as those participants who scores MMSE-C $\leq 24$. GD (Geriatric Depression) Scale was used for assessing the depression and the instrumental activities of daily living (IADL) was measured in terms of Lawton Scale.

Trop J Pharm Res, September 2018; 17(9): 1868 
Table 1: Baseline gender-based socio-demographic characteristics of the study subjects

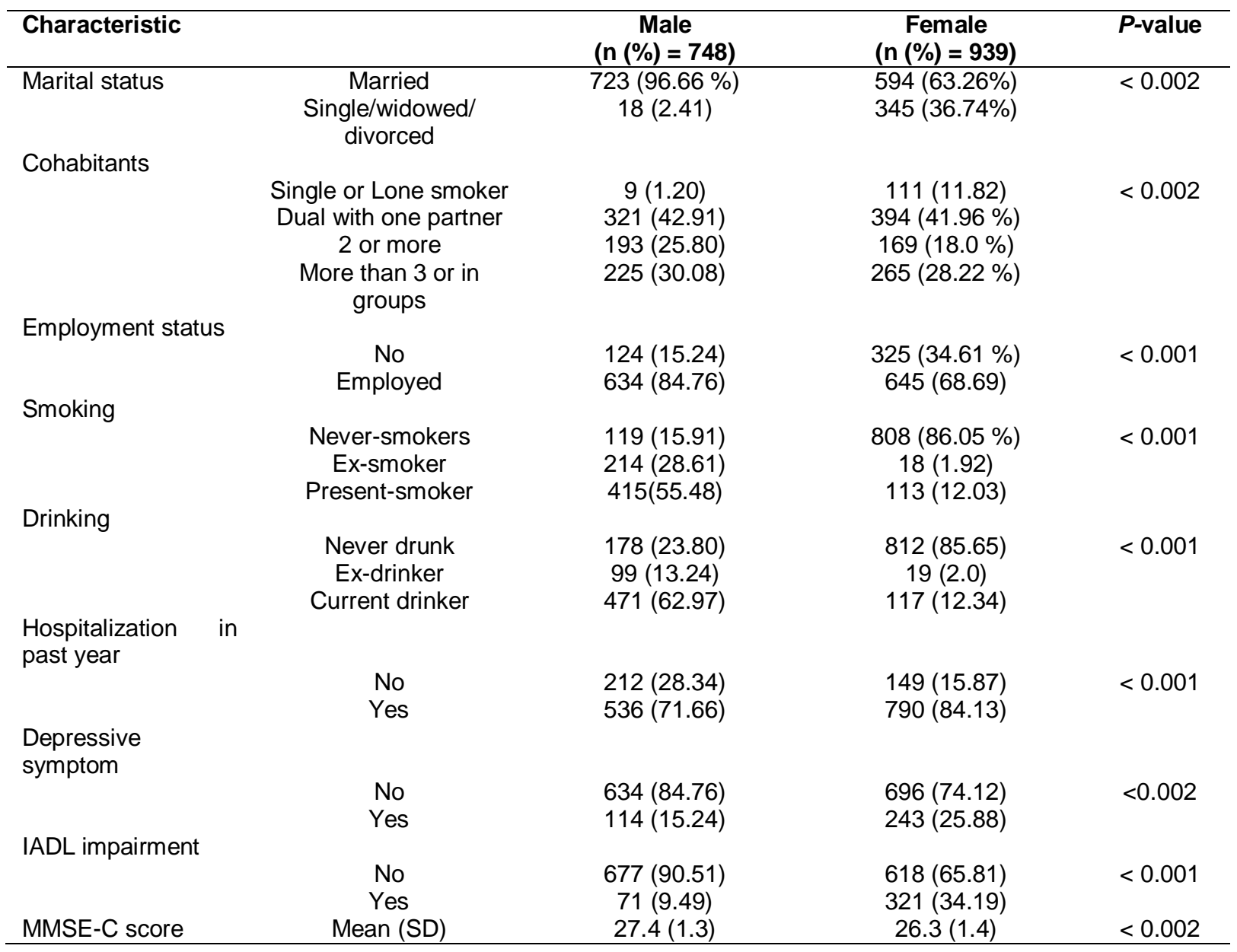

\section{Data analysis}

Statistical analyses were carried out using the IBM SPSS Statistics 20 (SPSS, Inc, USA). The socio-demographic characteristics of the 1687 participants without cognitive decline are described in percentage and amount. The chisquare test was used to evaluate the social and demographic characteristics of the subjects which develop cognitive decline as well as those subjects which did not develop cognitive decline. Multiple logistic regressions (MLR) analysis was carried out to evaluate the independent factors associated with the cognitive decline between smoking and alcohol consumption. The MLR logistic modeling allows to carry out two binary comparisons simultaneously. Within each comparison, the odds ratio (OR) and confidence interval ( $95 \%)$, was calculated by comparing to a control group. The control group was considered as an index of the relationship between cognitive decline and smoking/alcohol consumption. The control groups in this study are the non-drinkers and non-smokers.

Gender-based evaluations were carried out on the levels of smoking and alcohol consumption which may be the reason for developing cognitive decline during the 6 years follow-up.

The dose-dependent relationship was evaluated for determining the $\mathrm{P}$ for trend. The trend test was carried for estimating the amount of smoked cigarettes in packets per year and the total amount of alcohol consumption per week. Statistical analyses were adjusted for genderbased analysis, drinking and smoking cohabitants, MMSE-C score baseline, IADL impairment, and the status of smoking and alcohol consumption.

\section{RESULTS}

Table 1 shows the gender-based social, clinical and demographic characteristics of the volunteered elderly population. The results observed a significant difference in the malefemale characteristics distribution. The comparative analysis of the male-female gender based on socio-demographic characteristics on the development of cognitive decline is shown in Table 2.

Trop J Pharm Res, September 2018; 17(9): 1869 
Table 2: Socio-demographic characteristics of the study subjects at baseline based on the development of dementia and cognitive decline

\begin{tabular}{|c|c|c|c|c|}
\hline Characteristic & & $\begin{array}{c}\text { Participants without } \\
\text { dementia and cognitive } \\
\text { decline at follow up (n } \\
(\%)=1138)\end{array}$ & $\begin{array}{c}\text { Participants with } \\
\text { dementia and cognitive } \\
\text { decline at follow up (n } \\
(\%)=549)\end{array}$ & $P$-value \\
\hline Gender & & & & \\
\hline & Male & $621(54.57)$ & $143(26.05)$ & $<0.002$ \\
\hline & Female & $517(45.43)$ & 406 (73.95) & \\
\hline Marital status & Married & $971(8533)$ & $404(7359)$ & $<0,001$ \\
\hline & Single/ & 167 (14.67) & $145(26.41)$ & \\
\hline & $\begin{array}{l}\text { widowed/ } \\
\text { divorced }\end{array}$ & & & \\
\hline Cohabitants & & & & \\
\hline & 0 & $66(5.80)$ & $57(10.40)$ & $<0.002$ \\
\hline & 1 & 491 (43.15) & $247(45.07)$ & \\
\hline & & $249(21.88)$ & 95 (17.34) & \\
\hline & 3 or more & $332(29.17)$ & 149 (27.19) & \\
\hline Employment sta & & & & \\
\hline & No & $263(23.11)$ & $144(26.23)$ & $<0.021$ \\
\hline & Employed & 875 (76.89) & 405 (73.77) & \\
\hline Smoking & & & & \\
\hline & Never & $\begin{array}{c}09(53.51) \\
180(1582)\end{array}$ & $\begin{array}{r}351(63.93) \\
47(8.56)\end{array}$ & \\
\hline & Present-smoker & 349 (30.67) & $151(27.50)$ & \\
\hline Drinkıng & & & & \\
\hline & Never & 629 (55.27) & $355(64.66)$ & \\
\hline & Ex-drinker & $88(7.73)$ & $33(6.01)$ & \\
\hline & Current drinker & 421 (36.99) & 161 (29.33) & \\
\hline $\begin{array}{l}\text { Hospitalization } \\
\text { year }\end{array}$ & & & & \\
\hline & No & 245 (21.53) & 106 (19.31) & $<0.381$ \\
\hline & Yes & 893 (78.47) & 443 (80.69) & \\
\hline Depressive sym & & & & \\
\hline & No & 891 (85.84) & $374(68.12)$ & $<0.001$ \\
\hline & Yes & $147(14.6)$ & $175(31.88)$ & \\
\hline IALL IIIPAImImen & No & $898(86.51)$ & $332(60.47)$ & $<0.001$ \\
\hline & Yes & 140 (13.49) & 217 (39.53) & \\
\hline MMSE-C score & Mean (SD) & $27.2(1.3)$ & $26.5(1.4)$ & $<0.001$ \\
\hline
\end{tabular}

The study also observed that 549 subjects developed cognitive decline during the six-year study period. Mostly female subjects 406 (73.95 $\%$ ) developed cognitive decline with a majority being unemployed and consume alcohol. They also tend to possessed symptoms of depression with a lower MMSE-C score $(p<0.05)$.

In Table 3, it is observed that present-smoker have a higher risk of cognitive decline compared to non-smokers (Odds ratio $=1.51 ; \mathrm{Cl}$ at $95 \%=$ 1.07 - 2.11). While the smokers with a low amount of pack-years observed an increased in the odds ratio. Therefore they tend to have a higher risk of developing cognitive decline compared to non-smokers (Odds ratio $=1.56 ; \mathrm{Cl}$ at $95 \%=1.08-2.17$ ), as shown in Table 3 . However, there was no statistically significant difference between high pack-years smokers and cognitive decline (OR, 1.28; $95 \% \mathrm{Cl}, 0.84-$ 2.01) (Table 3).

The study also observed that the female subjects possessed significant effects of smoking on developing cognitive decline. The odds for the female present-smokers in the development of cognitive decline was $1.51(\mathrm{Cl}$ at $95 \%=1.02-$ 2.49) (Table 3) compared to non-smokers. The female subjects who consume a higher packet of cigarette per year were found to be almost doubled the chances of developing cognitive decline compared to non-smokers (Odds ratio $=$ 2.35; $\mathrm{Cl}$ at $95 \%=1.27-4.28)$. Thus, indicating a dose-dependent relationship $(p=0.003)$.

In Table 4, the association of drinking and its effect on cognitive decline is presented. A nonlinear relationship was observed on the association of drinking and cognitive decline. 
Table 3: MLR analysis reflecting the progression of smoking status of the participants during their age from 60-65 years on the development of cognitive decline after the 6-year study period

\begin{tabular}{|c|c|c|c|c|c|c|c|}
\hline Variable & & $\begin{array}{c}\text { Total } \\
\text { OR }\end{array}$ & $\begin{array}{c}\text { Total } \\
\mathrm{Cl} \text { at } 95 \%\end{array}$ & $\begin{array}{c}\text { Males } \\
\text { OR }\end{array}$ & $\begin{array}{c}\text { Males } \\
\mathrm{Cl} \text { at } 95 \%\end{array}$ & $\begin{array}{c}\text { Females } \\
\text { OR }\end{array}$ & $\begin{array}{l}\text { Females } \\
\mathrm{Cl} \text { at } 95 \%\end{array}$ \\
\hline \multicolumn{8}{|l|}{ Baseline } \\
\hline & $\begin{array}{l}\text { Non- } \\
\text { smoker }\end{array}$ & 1 & (Control) & 1 & (Control) & 1 & (Control) \\
\hline & $\begin{array}{l}\text { Ex- } \\
\text { smoker }\end{array}$ & 1.32 & $(0.85-2.11)$ & 1.01 & $(0.51-1.83)$ & 2.07 & $(0.71-5.96)$ \\
\hline & $\begin{array}{l}\text { Present- } \\
\text { smoker }\end{array}$ & 1.51 & $(1.07-2.11)$ & 1.23 & $(0.71-2.19)$ & 1.51 & $(1.02-2.49)$ \\
\hline \multicolumn{8}{|c|}{$\begin{array}{l}\text { Number of } \\
\text { pack- } \\
\text { years }\end{array}$} \\
\hline & $\begin{array}{l}\text { Never } \\
\text { Low } \\
\text { High }\end{array}$ & $\begin{array}{c}1 \\
1.56 \\
1.28\end{array}$ & $\begin{array}{c}\text { (Control) } \\
(1.08-2.17) \\
(0.84-2.01)\end{array}$ & $\begin{array}{c}1 \\
1.29 \\
1.15\end{array}$ & $\begin{array}{c}\text { (Control) } \\
(0.74-2.27) \\
(0.61-2.15)\end{array}$ & $\begin{array}{c}1 \\
1.25 \\
2.35\end{array}$ & $\begin{array}{c}\text { (Control) } \\
(0.71-2.14) \\
(1.27-4.28)\end{array}$ \\
\hline $\begin{array}{l}P \text { for } \\
\text { trend }(P)\end{array}$ & & 0.342 & & 0.978 & & 0.003 & \\
\hline
\end{tabular}

Table 4: MLR analysis on the progression of alcohol consumption and development of cognitive decline during the 6-year study period

\begin{tabular}{|c|c|c|c|c|c|c|c|}
\hline Variable & & $\begin{array}{c}\text { Total } \\
\text { OR }\end{array}$ & $\begin{array}{c}\text { Total } \\
\mathrm{Cl} \text { at } 95 \%\end{array}$ & $\begin{array}{c}\text { Male } \\
\text { OR }\end{array}$ & $\begin{array}{c}\text { Male } \\
\mathrm{Cl} \text { at } 95 \%\end{array}$ & $\begin{array}{c}\text { Female } \\
\text { OR }\end{array}$ & $\begin{array}{c}\text { Female } \\
\mathrm{Cl} \text { at } 95 \%\end{array}$ \\
\hline \multicolumn{8}{|l|}{$\begin{array}{l}\text { Baseline- } \\
\text { Drinking }\end{array}$} \\
\hline & $\begin{array}{l}\text { Non-Drinker } \\
\text { Ex-Drinker } \\
\text { Present-Drinker }\end{array}$ & $\begin{array}{c}1 \\
1.06 \\
1.06\end{array}$ & $\begin{array}{c}\text { (Control) } \\
(0.64-1.76) \\
(0.79-1.43)\end{array}$ & $\begin{array}{c}1 \\
1.66 \\
1.51\end{array}$ & $\begin{array}{c}\text { (Control) } \\
(0.86-3.20) \\
(0.92-2.47)\end{array}$ & $\begin{array}{c}1 \\
0.62 \\
0.83\end{array}$ & $\begin{array}{c}\text { (Control) } \\
(0.24-1.62) \\
(0.55-1.27)\end{array}$ \\
\hline \multicolumn{8}{|l|}{$\begin{array}{l}\text { Amount of } \\
\text { drinking } \\
\text { per week }\end{array}$} \\
\hline $\begin{array}{l}P \text { for trend } \\
\text { (P) }\end{array}$ & $\begin{array}{l}\text { Never } \\
\text { Non-Regular } \\
\text { Regular }\end{array}$ & $\begin{array}{c}1 \\
0.89 \\
1.31 \\
0.157\end{array}$ & $\begin{array}{c}\text { (Control) } \\
(0.65-1.24) \\
(0.91-1.89)\end{array}$ & $\begin{array}{c}1 \\
1.29 \\
1.66 \\
0.042\end{array}$ & $\begin{array}{c}\text { (Control) } \\
(0.75-2.23) \\
(1.98-2.75)\end{array}$ & $\begin{array}{c}1 \\
0.69 \\
1.17 \\
0.611\end{array}$ & $\begin{array}{c}\text { (Control) } \\
(0.45-1.04) \\
(0.54-2.59)\end{array}$ \\
\hline
\end{tabular}

The result also observed that regular alcohol consumption has a higher risk of developing cognitive decline (Odds ratio = 1.69; $\mathrm{Cl}$ at $95 \%=$ 1.03 - 2.75). Among the male subjects, a dosedependent relationship was established on the association of alcohol consumption and cognitive decline $(p=0.042)$. But in the case of female non-regular drinkers, there was a lesser chance of developing cognitive decline (Odds ratio = 0.69 ; $\mathrm{Cl}$ at $95 \%=0.45-1.04)$.

\section{DISCUSSION}

The study observed a significant difference in the development of cognitive impairment in the studied population amongst the male and female population. The study also observed that cognitive impairment was associated with those persons with drinking and smoking habits in their early 60s. Those women who never smoke in their lifetime had a lesser chance of developing dementia and cognitive decline.
The higher risk among the female smokers also suggests that they tend to developed cognitive impairment in a cumulative manner. However, this was different in case of males. There was a non-linear relationship between alcohol consumption and cognitive decline in females. However, among the male subjects, a dosedependent relationship was observed with respect to alcohol consumption. Thus these subjects have a higher possibility of developing cognitive impairment.

There are several reports on the association of smoking, alcohol consumption and cognitive impairment with different results and views. Nao et al observed that smoking is associated with mild cognitive impairment in diabetic patients [14]. On the contrary, Ikeda et al observed that smoking diminish the chances of cognitive impairment and the risk for dementia [15]. In addition, Kardani et al proposed that the 
presence of nicotine in cigarettes activates the nicotinic acetylcholine receptors and stimulates its neuroprotective role and dopaminergic effect [16].

However, recent studies on the magnetic resonance imaging (MRI) of cigarette smokerelated effects on human brain structure have suggested smoking adversely affected the structural integrity of multiple sub-cortical brain regions. Thus increases the chance of dementia, Alzheimer's disease and cognitive decline [17].

A case-control and cohort studies on the association of smoking and Alzheimer's disease showed conflicting results. A meta-analysis of the case-control study suggests that a history of smoking is associated with an increased incidence of Alzheimer's disease especially in those subjects who are current smokers during the follow-up period [18].

Anstey et al also reported that current-smokers above 65 years are at the risk of dementia and cognitive decline compared to never-smoker subjects. The workers also suggest that there is not enough parameters and data on determining risk effects of cognitive decline and dementia in ex-smokers or past-smokers. However, their study proposed that cognitive outcomes should be measured in clinical trials [19]. The results of the present investigation observed that our findings are inconsistent with those of the previous study by Durazzo et al and Anstey et al $[18,19]$. However, in our study, the chances of developing cognitive impairment in presentsmokers were common among the females. However, no significant relationship was observed in the male subjects in terms of cognitive impairment and smoking cigarette [20].

When it comes to gender study, Travis et al observed the susceptibility of lung cancer in female smokers because of tar exposure compared to male counterparts [21]. Similarly, our study also suggests that female smokers are more prone in developing cognitive decline compared to male smokers which may be due to the fast rate of nicotine metabolism by the female hormones and its effect on the cognitive decline [22]. Additionally, females exhibited a higher amount of nicotine intake and the total plasma clearance of nicotine is lower compared to males [23].

However, oestrogen which is the primary female sex hormone increases the neuronal function and its neurotransmitter system. Thus, it caused a positive effect on cognitive function [24]. The female subjects in our study possess a low oestrogen level because they are aged above 60 years. Hence, these female subjects developed cognitive decline because of the oxidative stress of smoking and menopause [24]. Also, the oxidative stress caused by smoking deteriorates their cognitive health.

There are also studies which observed that moderate amount of drinking alcohol reduced the risk of dementia and cognitive decline [25] Well these results are in comparison with both nondrinkers and regular-drinker, although there is certain contrasting results [25,26]. Wardzala et al reported that moderate use of alcohol reduces the risk of cardiovascular diseases. The beneficial effect may be because of the increase in the prostaglandin 12 thereby inhibiting the platelet activation and thus acts as an effective vasodilator. Wardzala et al further reported that men with moderate alcohol consumption experienced an extensive range of beneficial effects associated with alcohol [9].

However, frequent alcohol consumers tend to develop a harmful effect on the cognitive decline because of the neurotoxin from the ethanolic toxic substance. In this study, a direct relation between baseline alcohol drinking and cognitive decline among the studied participants was not observed. But the effects of drinking alcohol associated with cognitive impairment were observed in females. Among the males, there was a consistent relationship between the amounts of alcohol consumption per week and cognitive impairment. On the contrary, there was a low risk of cognitive decline among the females having a moderate level of alcohol drinking. Thus, presenting a non-linear relationship between a moderate level of alcohol drinking and the development of cognitive decline. LópezCaneda et al also observed that there was a positive relationship between moderate alcohol drinking and cognitive impairment among females and women performed better than men on mental flexibility. On the other hand, their study also observed that men performed better than women on visual processing [27]. In the present study, the standard amount of alcohol consumption was unable to determine because it was measured on weekly basis. Among the females the frequency of alcohol consumption showed a non-linear relationship. However, a direct association was observed in the male subjects that explained the gender-based dissimilar pattern in alcohol consumption.

\section{Limitations of the study}

The limitations of the study are that the details of smoking and drinking alcohol were based on 
self-reported data. Moreover, the amount of alcohol consumption was measured per week and not on the volume. Lastly, the changes in the smoking and alcohol consumption pattern were not measured in this study.

\section{CONCLUSION}

Female smokers in the age group of $60-65$ years who drink alcohol have the risk of developing cognitive decline and dementia. However, taking into consideration among male and female population and the factors which depend on their lifestyle, further investigation is required with much larger population and sample size. There is also an urgent need for establishing personalized living style modification, food habits and other strategies to prevent cognitive impairment effectively.

\section{DECLARATIONS}

\section{Acknowledgement}

The authors acknowledge Shaanxi Provincial People's Hospital, Xi'an, Shanxi, China for logistic support.

\section{Conflict of interest}

No conflict of interest is associated with this work.

\section{Contribution of authors}

We declare that this work was done by the authors named in this article and all liabilities pertaining to claims relating to the content of this article will be borne by the authors. Yingying Fu and Xiaoli Chen contribute to this work equally.

\section{REFERENCES}

1. Li J, Chang YP, Riegel B, Keenan BT, Varrasse M, Pack Al, Gooneratne NS. Intermediate, But Not Extended, Afternoon Naps May Preserve Cognition in Chinese Older Adults. J Gerontol A Biol Sci Med Sci 2018; 73: 360-366.

2. Stefanidis KB, Askew $C D$, Greaves K, Summers MJ. The Effect of Non-Stroke Cardiovascular Disease States on Risk for Cognitive Decline and Dementia: A Systematic and Meta-Analytic Review. Neuropsychol Rev 2017; 28 : 1-15.

3. Solfrizzi $V$, Custodero $C$, Lozupone $M$, Imbimbo $B P$, Valiani $V$, Agosti $P$, Schilardi $A$, D'Introno $A$, La Montagna M, Calvani M, et al. Relationships of Dietary Patterns, Foods, and Micro- and Macronutrients with Alzheimer's Disease and Late-Life Cognitive Disorders:
A Systematic Review. J Alzheimers Dis 2017; 59(3): 815-849.

4. $X u W$, Wang $H$, Wan $Y$, Tan $C$, Li J, Tan L, Yu JT. Alcohol consumption and dementia risk: a doseresponse meta-analysis of prospective studies. Eur $J$ Epidemiol 2017; 32(1): 31-42.

5. Lenoir M, Starosciak AK, Ledon J, Booth C, Zakharova E, Wade $D$, Vignoli $B$, Izenwasser $S$. Sex differences in conditioned nicotine reward are age-specific. Pharmacol Biochem Behav 2015; 28: 56-62.

6. Rha EY, Kim HJ, Han K, Park Y, Yoo G. Gender-specific relationship between alcohol consumption and injury in the South Korean adults: A nationwide cross-sectional study. Medicine (Baltimore) 2017; 96(14): e5385.

7. Bellou V, Belbasis L, Tzoulaki I, Middleton $L T$, loannidis $J P$, Evangelou E. Systematic evaluation of the associations between environmental risk factors and dementia: An umbrella review of systematic reviews and meta-analyses. Alzheimers Dement 2017; 13(4): 406418.

8. Gu YJ, He CH, Li S, Zhang SY, Duan SY, Sun HP, Shen $Y P, X u Y$, Yin JY, Pan CW. Tea consumption is associated with cognitive impairment in older Chinese adults. Aging Ment Health 2017; 21: 1-7.

9. Wardzala C, Murchison C, Loftis JM, Schenning KJ, Mattek N, Woltjer R, Kaye J, Quinn JF, Wilhelm CJ. Sex differences in the association of alcohol with cognitive decline and brain pathology in a cohort of octogenarians. Psychopharmacology (Berl) 2017; 235: 761-770.

10. Lee E, Daugherty J, Burkard J. Correlational Study of Sleep Apnea Patient Characteristics With Discharge Locations. J PerianesthNurs2016; 31(5): 381-391.

11. World Medical Association. Declaration of Helsinki: Ethical Principles for Medical Research Involving Human Subjects. JAMA2013; 310 (20): 2191-2194.

12. Park B, Park J, Jun JK, Choi KS, Suh M Gender Differences in the Association of Smoking and Drinking with the Development of Cognitive Impairment. PLoS ONE 2013; 8(10): e75095.

13. Zeng $Y$, Vaupel JW. Functional capacity and selfevaluation of health and life of oldest old in China. J Soc 2002; 58: 733-748.

14. Sonoda N, Morimoto A, Ugi S,Morino K, Sekine O, Nemoto Kl, Maegawa H, Miyamatsu N. Smoking status is associated with mild cognitive impairment assessed with the mini-mental state examination in Japanese diabetic patients. Diabetol Int 2016; 7(4): 361-367.

15. Ikeda A, Yamagishi K, Tanigawa T. Cigarette smoking and risk of disabling dementia in a Japanese rural community: a nested case-control study. Cerebrovasc Dis 2008; 25: 324-331.

16. Kardani J, Sethi R, Roy I. Nicotine slows down oligomerisation of $\alpha$-synuclein and ameliorates cytotoxicity in a yeast model of Parkinson's disease. Biochim Biophys Acta2017; 1863(6):1454-1463.

17. Durazzo TC, Meyerhoff DJ, Yoder KK, Murray DE. Cigarette smoking is associated with amplified age-

Trop J Pharm Res, September 2018; 17(9): 1873 
related volume loss in subcortical brain regions. Drug Alcohol Depend 2017; 177: 228-236.

18. Almeida OP, Hulse GK, Lawrence D, Flicker L. Smoking as a risk factor for Alzheimer's disease: contrasting evidence from a systematic review of case-control and cohort studies. Addiction 2002; 97: 15-28.

19. Anstey KJ, von Sanden C, Salim A, O'Kearney $R$. Smoking as a risk factor for dementia and cognitive decline: a meta-analysis of prospective studies. Am J Epidemiol2007; 166: 367-378.

20. Van den Berg JF, Dogge B, Kist N, Kok RM, Van der Hiele K. Gender Differences in Cognitive Functioning in Older Alcohol-Dependent Patients. Subst Use Misuse 2017; 52(5):574-580.

21. Meyers TJ, Chang SC, Chang PY, Morgenstern $H$, Tashkin DP, Rao JY, Cozen W, Mack TM, Zhang ZF Case-control study of cumulative cigarette tar exposure and lung and upper aerodigestive tract cancers. Can Epidemiol 2017; 140(9): 2040-2050.

22. Flores RJ, Uribe KP, Swalve $N$, O'Dell LE. Sex differences in nicotine intravenous self-administration: $A$ meta-analytic review. Physiol Behav 2017; 45: S00319384.
23. Krebs NM, Allen SI, Veldheer $S$, Martinez DJ, Horn $K$, Livelsberger C, Modesto J, Kuprewicz R, Wilhelm A, Hrabovsky $S$, et al. Reduced nicotine content cigarettes in smokers of low socioeconomic status: study protocol for a randomized control trial. Trials 2017; 18(1):300309.

24. Crider A, Pillai A. Estrogen Signaling as a Therapeutic Target in Neurodevelopmental Disorders. J Pharmacol Exp Ther 2017; 360(1): 48-58.

25. Anstey KJ, Mack HA, Cherbuin N. Alcohol consumption as a risk factor for dementia and cognitive decline: meta-analysis of prospective studies. Am $J$ Geriatr Psychiatry 2009; 17(7): 542-555.

26. Rehm J, Gmel GE, Gmel G, Hasan OSM, Imtiaz S, Popova S, Probst $C$, Roerecke $M$, Room $R$, Samokhvalov AV, Shield KD, Shuper PA. The relationship between different dimensions of alcohol use and the burden of disease-an update. Addiction 2017; 112(6): 968-1001.

27. López-Caneda E, Rodríguez Holguín S, Cadaveira F, Corral M, Doallo S. Impact of alcohol use on inhibitory control (and vice versa) during adolescence and young adulthood: A review. Alcohol 2014; 49(2): 173-181. 